\title{
ESTIMATION OF PRIOR-AUSTENITE GRAIN SIZE IN HEAT TREATED MARTENSITIC CARBON AND LOW ALLOY STEELS
}

Richard A. Schreiman, Buehler Ltd. Research and Development Laboratory, Lake Bluff, IL 60044 Wendy J. Bolton, Gulf Coast Laboratory Services, Houston, TX 77429

Determination of grain size is one of the most important metallographic measurements due to the influence of grain size on mechanical properties and behavior. Practical approaches for grain size determinations include estimation by comparison using standard templates, overlays, and/or reticles; as well as by direct and indirect measurement of microstructural constituents. These procedures are described in detail in ASTM E112, Standard Test Methods for Determining Average Grain Size.

Commercial and production metallurgical laboratories are often required to perform prior-austenite grain size determinations on martensitic steel components that have already been heat treated. However, standard steelmaking methods for determination of the prior-austenite grain size (such as McQuaid-Ehn carburizing, oxidation, copper diffusion, and thermal etching) are irrelevant for steel that has already been hardened. Although these methods may occasionally be mandated by material or procedural specifications, they are typically not considered preferable methods because the processes have a tendency of altering the as-received microstructure [1]. They also can be laborintensive and/or cost-prohibitive. In these instances, the most time-efficient and cost-effective methodologies for estimating grain size involve utilization of etching techniques to preferentially delineate the prior-austenite grain boundaries [2]. Unfortunately, revealing prior-austenite grain boundaries may be difficult, and requires special etchants that do not always work well, and do not always reveal a high percentage of the grain boundaries.

This paper shall discuss specimen preparation and preferential etching techniques that will facilitate labor-efficient, cost-effective measurement methodologies and accurate grain size estimations for martensitic carbon and low alloy steel components. Inherent difficulties in achieving complete delineation of the prior-austenite grain boundaries, and the associated difficulties in reconstruction of complete grain boundaries for image evaluation and processing shall also be discussed.

Figure 1 depicts the preferential etching of AISI 43B17 low alloy steel in the quenched and tempered condition. Complete delineation of the prior austenite grain boundaries was achieved, and grain size was estimated via comparison to standard templates, as well as by image analysis.

Figure 2 depicts the preferential etching of quenched and tempered AISI 4140 low alloy steel. Due to incomplete delineation of the prior austenite grain boundaries, grain boundary reconstruction shall be necessary in order to evaluate the grain size using image analysis techniques. However, an accurate estimation may still be made via comparison to standard grain size templates.

[1] R. Millsop, “A Survey of Austenite Grain Size Measurements”, Hardenability Concepts with Applications to Steels, TMS-AIME, Warrendale, PA, 1978, pp. 316-333.

[2] G. Vander Voort, Metallography Principles and Practice, McGraw-Hill, 1984, p. 436. 


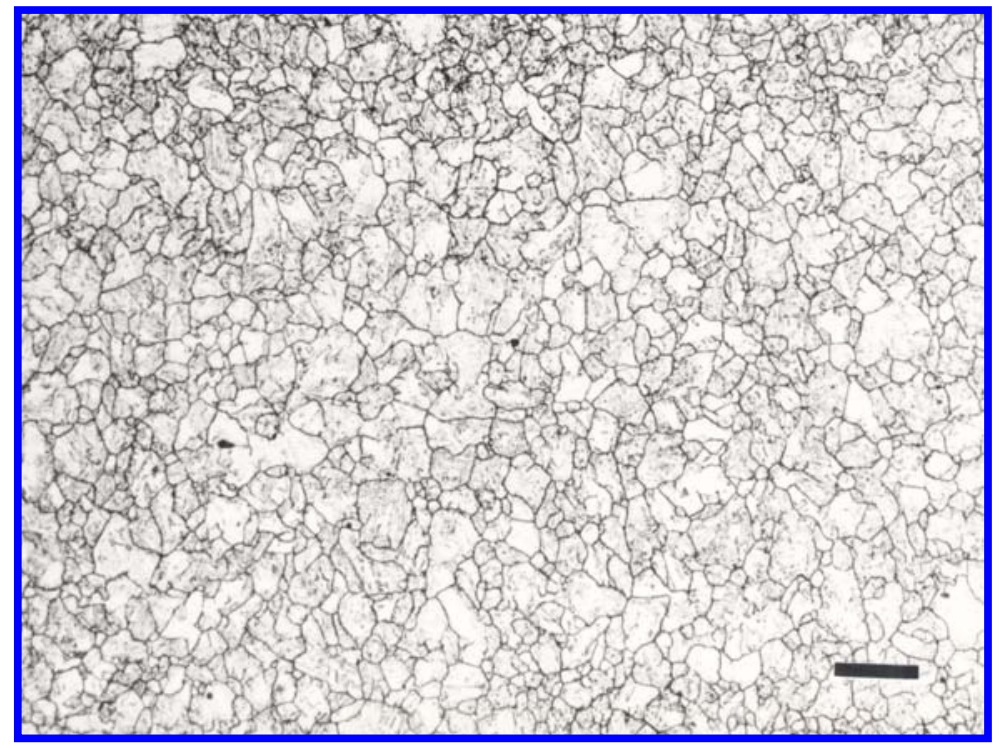

FIGURE 1: Prior-austenite grain boundaries in 43B17 alloy steel revealed by etching with aqueous saturated picric acid plus $1 \% \mathrm{HCl}$ and a wetting agent (magnification bar: $50 \mu \mathrm{m}$ ).

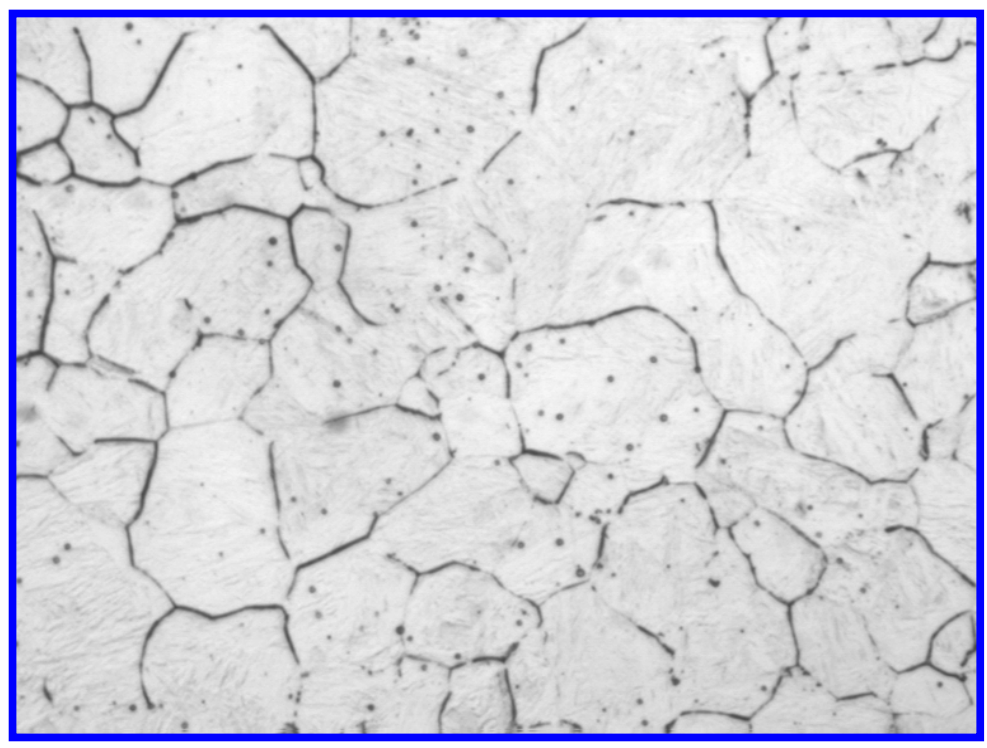

FIGURE 2: Incomplete delineation of prior austenite grain boundaries in AISI 4140 quench and tempered low alloy steel. Etched using saturated picric solution and $2 \mathrm{ml}$ sodium dodecylbenzene sulfonate as a wetting agent $(\sim 500 \mathrm{x})$. 